\title{
Alcohol-Induced Neuropathy in Chronic Alcoholism: Causes, Pathophysiology, Diagnosis, and Treatment Options
}

\author{
Iga Dudek ${ }^{1} \cdot$ Danuta Hajduga $^{1} \cdot$ Cezary Sieńko $^{1} \cdot$ Amr Maani $^{2} \cdot$ Elżbieta Sitarz $^{3} \cdot$ Monika Sitarz $^{4} \cdot$ Alicja Forma $^{1}$ (D
}

Accepted: 12 October 2020 / Published online: 23 October 2020

(C) The Author(s) 2020

\begin{abstract}
Purpose of the Review Alcohol abuse causes a wide range of disorders that affect the nervous system. These include confusion, cerebellar ataxia, peripheral neuropathy, and cognitive impairment. Chronic and excessive alcohol consumption is the primary cause of peripheral neuropathy. It is worth noting that peripheral neuropathy has no reliable treatment due to the poor understanding of its pathology.

Recent Findings Coasting is a major feature of alcoholic neuropathy, largely due to chronic alcohol abuse. Its major features are hyperalgesia, allodynia, and burning pain. Even though much research was done in this area, still we do not have a full understanding of the mechanism of alcoholic neuropathy. However, some theories have been proposed. These include direct or indirect effects of alcohol metabolites, impaired axonal transport, suppressed excitatory nerve pathway activity, or imbalance in neurotransmitters. Activation of spinal cord microglia, mGlu5 spinal cord receptors, and hypothalamic-pituitary-adrenal axis also seem to be implicated in the pathophysiology of this alcoholic neuropathy. The goal of treatment is to impede further damage to the peripheral nerves while also restoring their normal physiology. Alcohol abstinence, intake of balanced diets, and treatment with medications are suggested including benfotiamine, alpha-lipoic acid, acetyl-L-carnitine, vitamin E, methylcobalamin, myo-inositol, $N$-acetylcysteine, capsaicin, tricyclic antidepressants, or antiepileptic drugs.

Summary This review focuses on the many pathways that play a role in the onset and development of alcohol-induced neuropathy, as well as present the possible treatment strategies of this disorder, providing insights into a further search of new treatment modalities.
\end{abstract}

Keywords Alcohol $\cdot$ Neuropathy $\cdot$ Peripheral nervous system $\cdot$ Autonomic nervous system $\cdot$ Ethanol $\cdot$ Alcohol metabolites

This article is part of the Topical Collection on The Pathobiology of Alcohol Consumption

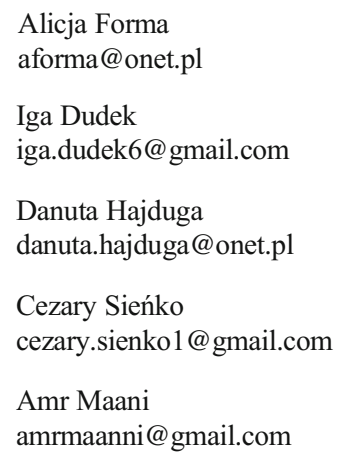

Elżbieta Sitarz

elzbietaa.sitarz@gmail.com

1 Chair and Department of Forensic Medicine, Medical University of Lublin, 20-090 Lublin, Poland

2 Chair and Department of Human Anatomy, Medical University of Lublin, 20-090 Lublin, Poland

3 Chair and 1st Department of Psychiatry, Psychotherapy and Early Intervention, Medical University of Lublin, 20-439 Lublin, Poland

4 Department of Conservative Dentistry with Endodontics, Medical University of Lublin, 20-090 Lublin, Poland 


\section{Introduction}

Alcohol-related diseases are caused by excessive consumption of alcohol. Alcohol-related ailments occur either with or without coexisting nutritional or vitamin deficiencies [1]. Excessive alcohol abuse seems to be the motivational drive for further lifetime drinking in excessive amounts that might ultimately lead to alcohol-induced neuropathy. Alcohol abuse and chronic pain associated with alcohol-related neuropathy present high comorbidity $[2 \cdot \bullet]$. A recent report by the World Health Organization says that approximately 3 million people die each year due to alcohol abuse [3]. Total alcohol per capita of the world population over the age of 15 has increased from 5.51 of pure alcohol in 2005 to 6.41 in 2016. Excessive alcohol consumption is one of the major factors that increase the mortality rate primarily in males aged 15-59 particularly in Eastern Europe [4, 5]. Alcohol abuse is believed to contribute to the onset of over 60 types of diseases and injuries and a cause of at least 200 others at the same time [6]. Excessive alcohol consumption leads to the severe failures of digestive, cardiovascular, and nervous (central and peripheral) systems [6-10]. The most frequent disorders related to alcohol abuse include alcoholic liver disease (including steatosis, steatohepatitis, cirrhosis, or hepatocellular carcinoma), pancreatitis, gastritis, hypertension, arrhythmia, or cardiomyopathy [11-21]. The prevalence of the alcoholic liver disease among heavy drinkers is estimated at $15-30 \%$ [22]. Among disorders of the nervous system, Korsakoff's syndrome, anterograde amnesia, cerebellar ataxia, sleep disorders, cognitive deficits, and alcohol neuropathy are of the highest prevalence [23-26, 27••, 28-30]. Besides, alcohol consumption significantly contributes to the onset of cancers such as a cancer of the oral cavity, pharynx, larynx, esophagus, liver, or colon. Toxic and metabolic effects of alcohol vary depending on age, dose, and duration of exposure [31]. Neuropathies, regardless of etiology, are fairly common especially among the elderly, attaining an $8 \%$ prevalence rate $[32,33]$. Besides the alcohol, neuropathies may be induced by various factors including toxins (chemotherapeutic agents, heavy metals, industrial chemicals), infections (borreliosis, HIV), the course of metabolic diseases (diabetes, uremia, acromegaly), or they may be related to systemic diseases such as sarcoidosis, polyarteritis nodosa, or rheumatoid arthritis [34-44]. Idiopathic neuropathy, designated as chronic idiopathic axonal polyneuropathy (CIAP), constitutes the most frequent neuropathy so far [45-47]. Besides, within the peripheral nervous system, neuropathies may be classified into mono-, poly-, and multifocal neuropathies [48].

Toxic effects of alcohol are associated with several mechanisms that include the direct or indirect activity of alcohol metabolites, oxidative stress induction, and the translocation of the intestinal endotoxins into the bloodstream. DNA, proteins, and lipids might be damaged due to acetaldehyde and oxidants produced during alcohol metabolism. Alcoholrelated tissue hypoxia and impaired mitochondrial functions and singling pathways are highly prevalent molecular consequences of alcohol abuse. Alcohol is metabolized by three pathways - by the alcohol dehydrogenase in the cytosol, the Microsomal Ethanol Oxidizing System (MEOS), and the catalase which is contained in peroxisomes (Fig. 1).

Alcohol-induced neuropathy, also known as alcoholrelated peripheral neuropathy (ALN), is a toxic polyneuropathy that leads to the damage of sensory, motor, and autonomic nerve fibers leading to the thinning of the myelin sheaths and further impairments of neural functions $[14,49]$. ALN is characterized by spontaneous burning pain, hyperalgesia, and allodynia. Regarding pain pathways, several pain-related receptors, such as $\delta$-opioid receptors, $\mathrm{K}$-opioid receptors, and nociception opioid receptors, are highly expressed within different regions including the peripheral nervous system, spinal cord, and the supraspinal regions, significantly contributing to the induction and further intensification of pain. Besides, the key mechanism of chronic pain includes the long-term potentiation of glutamatergic transmission. The percentage of alcohol-dependent patients affected by ALN is estimated to be $66 \%$ [50,51]. The pathophysiology of ALN involves underlying mechanisms that include direct or indirect effects of alcohol metabolites, impaired axonal transport, suppressed excitatory nerve pathway activity, or imbalance in neurotransmitters [52-54]. An essential risk factor regarding the etiology of ALN is the amount of alcohol consumed throughout the years since alcohol displays direct toxicity on nerve fibers [55]. It is estimated that consumption of more than $100 \mathrm{ml}$ of ethyl alcohol per day significantly increases the risk of ALN [56]. Recent studies show contradictory information about the role of malnutrition and micronutrients (thiamine) deficiency in the pathogenesis of ALN; however, it is assumed that these might induce the progression of ataxia or movement disorders [55, 57]. Nevertheless, heavy alcohol drinkers are usually significantly malnourished because of the improperly balanced diet and impaired absorption of the essential nutrients and elements $[58,59]$.

\section{Alcohol Abuse Diagnostic Criteria and Biomarkers}

Generally, alcohol abuse might be defined as the difficulties in the control of alcohol consumption or repetitive and continuous alcohol consumption. Diagnostic criteria for alcohol use disorder are highly differentiated; however, the most common criteria currently used are found in the Diagnostic and Statistical Manual of Mental Disorders (DSM-5). Except for DSM-5, diagnostic criteria of alcohol abuse were proposed by the International Classification of Diseases (11th revision) that 
Fig. 1 Three major pathways of alcohol metabolism

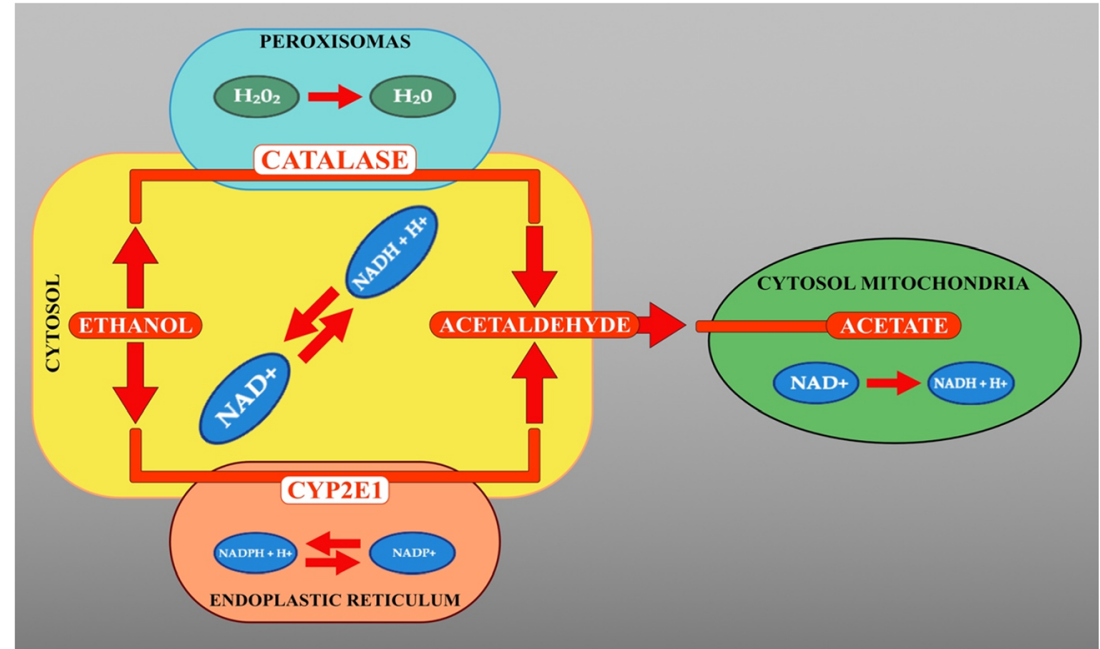

was updated in 2015. According to DSM-5, alcohol abuse might be diagnosed when at least two of the following symptoms appear in the 12-month period, and these are (1) greater alcohol intake or prolonged alcohol intake that was not initially intended, (2) unsuccessful efforts to control the amounts of alcohol consumed, (3) activities that aim to obtain alcohol, (4) a strong desire to use alcohol, (5) repetitive alcohol consumption and coexisting failures in the everyday life activities, (6) continuous alcohol consumption despite the appearing of the disturbed interpersonal relationships, (7) given up of crucial activities only to obtain alcohol, (8) alcohol abuse in physically hazardous situations, (9) the continuation of alcohol consumption being aware of its toxic side effects, (10) the appearance of alcohol tolerance, and (11) the appearance of a withdrawal syndrome. ICD-11 criteria proposed the following criteria: criterion A-difficulties in controlling alcohol consumption, criterion B-alcohol consumption becomes a priority of an addicted individual, and criterion $\mathrm{C}$ refers to the presence of physiological symptoms. Symptoms that are typical for alcohol abusers include poor coordination, inappropriate behavior and unstable moods, or impaired attention and/or memory. Besides, chronic and continuous intake of alcohol might induce the appearance of an alcohol withdrawal syndrome that includes such symptoms as nausea, vomiting, hallucinations, sweating, rapid heartbeat, anxiety, or seizures. Alcohol abusers are usually motivated for further drinking due to the induction of the neuroadaptive changes, primarily within the brain neurotransmissions systems, such excessive drinking further leads to the induction of physiological symptoms and other disorders such as ALN. Moreover, alcohol abusers with ALN tend to drink greater amounts of alcohol in order to alleviate neuropathic pain. Besides, alcohol is an effective analgesic that might contribute to the motivation for further drinking.

Biomarkers of alcohol abuse include carbohydratedeficient transferrin (CDT) and phosphatidylethanol (PEth).
CDT is an indirect metabolite of ethanol and constitutes either a marker of prolonged, heavy alcohol consumption or a marker of relapse. Peth on the other hand is a direct alcohol metabolite that can be measured to monitor alcohol consumption as well as for the identification of early signs of alcohol-related clinical manifestations. Other non-specific biomarkers useful in the diagnosis of alcohol use disorder are gamma-glutamyl transferase (GGT), mean corpuscular volume (MCV) of the red blood cells, and aspartate aminotransferase (AST) and alanine aminotransferase (ALT) levels.

\section{Diagnosis of Alcohol-Related Peripheral Neuropathy}

In order to diagnose ALN, usually, several tests are needed to be performed to provide a complete and reliable diagnosis. Besides blood chemistry test and complete blood count (CBC), esophagogastroduodenoscopy is needed when a patient vomits and has nausea for an unknown reason; X-rays of the gastrointestinal tract can also be performed. Electromyography and nerve conduction tests are performed in order to reveal signs of ALN. In some cases, a nerve biopsy is needed. Sensory functions and reflexes can be tested during a neurological examination.

\section{Alcohol-Related Peripheral Neuropathy - History of Discovery and Exact Definition}

The first reports about the possible role of excessive alcohol consumption and induction of ALN were introduced in 1787 [60]. The concept was supported by another study from 1822 [61]. Lettsom has observed that paralysis and hypoesthesia 
related to ALN presented a higher prevalence rate in lower limbs compared to upper limbs [60].

Toxic neuropathies may be classified into three distinct groups depending on the etiology: neuropathies with damaged perikaryon, myelopathies where alcohol affects Schwann cell proliferation and myelin formation, and distal axonopathy [62, 63]. In 1977, Behse and Buchtal examined the differences in the microscopic findings and nerve conduction of the sural nerves of 37 patients with ALN and 6 patients with neuropathy induced by malnutrition after gastrectomy [56]. The results have shown that distal axonopathy in patients with ALN affected both myelinated and unmyelinated fibers. The underlying manifestation of ALN is axonal degeneration of the neurons of both the sensory and motor systems, following damage to the neuronal cell bodies [64-68]. Small fiber neuropathy is a typical manifestation of early stages of ALN, while the prolonged course of the disease leads to the degeneration of larger fibers, axonal sprouting, and subsequent regeneration of fibers $[65,69]$. The majority of patients with ALN initially present with symmetrical polyneuropathy mainly in the lower distal extremities since primarily the initial manifestations occur in the most distal part of the axons [70]. Thus, longer axons are more prone to be initially affected [71]. During ALN progression, axonal transport is less effective and synaptic transmission is disrupted [72]. Further, retrograde degeneration or so-called dying back phenomenon occurs, reaching back the perikaryon in advanced stages of ALN [73, 74]. Burning and throbbing pain along with autonomic dysfunctions are induced mainly via the degeneration of unmyelinated $\mathrm{C}$ and $\mathrm{A} \delta$ fibers $[68,75]$. The dysfunctions within fibers of greater diameter manifest as a disturbed sense of vibration, proprioception, and impaired tendon reflexes [76].

\section{Intake of Alcohol}

Pathogenesis of ALN is related to either direct or indirect (or both) toxic effects of alcohol on nerve fibers. The probability of ALN manifestation increases with the duration of alcohol abuse $[77,78]$. ALN develops in a dose-dependent manner; thus, what is crucial is the total lifetime dose of ethanol (TLDE) [55, 71]. According to Ammendola et al. (2001), TLDE and duration of alcohol dependence make up the two most significant risk factors of ALN [77]. Vittadini et al. (2001) showed that the largest percentage of ALN was in patients who consumed wine [71]. It could be probably due to the need for larger amounts of wine to induce alcohol intoxication or because of the possible contamination such as lead, which also causes toxic effects [79]. However, Ferdinandis et al. (2008) did not show the relationship between the higher incidences of ALN among patients who consume illicit (contaminated) alcohol compared to legal spirit drinkers [80]. ALN is believed to be related to risk factors associated with the excessive intake of alcohol such as malnutrition, deficiency of nutrients and elements (thiamine in particular), or direct effects of alcohol metabolites on the cells and tissues; however, the exact mechanism has not been deciphered yet. ALN is more prevalent among heavy and chronic alcohol drinkers compared to those who drink alcohol only episodically. Several studies proved the higher incidence rate of ALN among females compared to males; besides, females tend to present greater severity of ALN symptoms [81].

\section{ALN Pathophysiology}

The exact pathophysiology of ALN has not been yet determined. Primarily, it was assumed that the progression of ALN symptoms is due to malnutrition and micronutrient deficiency (mainly B1 hypovitaminosis) [82, 83]. Indeed, these factors contribute to the progression of ALN symptoms; however, they do not constitute direct factors that manifest in ALN development [84]. Current postulation holds that dysfunctions within the central and peripheral nervous system are due to both direct and indirect toxic effects of alcohol [31, 85-87]. Indirect effects are mainly induced by vitamin deficiencies (B1, B2, B3, B5, B6, B7, B9, and B12) [84, 88].

Chronic alcohol consumption leads to malnutrition with dysfunctions in protein and lipid metabolism which affect the metabolic pathways and progression of ALN symptoms within the central and peripheral nervous systems [89]. The direct toxic effects of alcohol and its metabolites (mainly acetaldehyde) are crucial in ALN etiology [64]. Acetaldehyde is involved in neuronal damage $[90,91]$. It has been demonstrated that incubation of neural cells with advanced glycation end products of acetaldehyde (AA-AGE) induced dose-dependent degradation of neuronal cells while the addition of AA-AGE antibodies reduced neurotoxicity $[51,90]$. Other findings showed that decreased activity of aldehyde dehydrogenase leads to peripheral neuropathy $[76,91]$.

The mechanism of direct damage of nerve fibers due to alcohol intoxication remains unclear. Activation of spinal cord microglia, mGlu5 spinal cord receptors, and hypothalamicpituitary-adrenal axis appear to be implicated in this process [92-97]. Oxidative stress also leads to the indirect damage of nerve fibers via the release of free radicals and proinflammatory cytokines with protein kinase $\mathrm{C}$ and ERK kinase phosphorylation [98-101]. Besides, ALN is characterized by insulin and insulin-like growth factor (IGF) resistance, which results in impaired trophic factor signaling $[102,103]$.

Ethanol and its toxic metabolites affect neural metabolism including metabolic activities in the nucleus, lysosomes, peroxisomes, endoplasmic reticulum, and cytoplasm [104]. The morphological basis of post-alcoholic damage of neural tissue includes primary axonopathy and secondary demyelination of motor and sensory (especially small) fibers [105]. 
Demyelination is probably the effect of axoplasmic transmission slowdown; such degeneration so-called dying back bears semblance to Wallerian degeneration [64, 84]. An animal study on axonal transport in vitro using dorsal roots of the sciatic nerve showed decreased axonal transmission after long-term ethanol consumption [106]. In vivo study on rats showed impaired retrograde axonal transport [107, 108]. Thus, ALN might be induced by the combination of the effects of the direct activity of alcohol metabolites on the nerve fibers along with nutritional deficiencies primarily in a form of thiamine deficiency.

\section{Symptoms}

ALN develops slowly over months or years [109, 110]. ALN can manifest differently, and patients might experience one, two, or even more clinical manifestations of ALN. Patients who have ALN might present such symptoms as cramps, impaired movement of the limbs, muscle atrophy, muscle weakness, spasms, or contractions, loss of sensation, or feeling of tingling. Besides, the gastrointestinal and urinary systems are also affected and include the presence of diarrhea, constipation, nausea, swallowing difficulties, abdominal bloating, and urinary retention.

During the initial stages of ALN, the disease may appear asymptomatic and demonstrable only on electroneurographic investigation $[71,111,112]$. Because ALN is a lengthdependent axonopathy, it manifests mainly in a "stockingglove" form, affecting the lower extremities at the beginning $[28,113]$. The main symptoms of ALN include dysesthesia, paresthesia, numbness, and pain in the lower extremities which progressively reach higher parts of the body [114-117]. The pain is described as burning, cramp-like, or itching; also, a common symptom is a subjective feeling of cold in both feet [118-123]. The symptoms deteriorate through touch and pressure which intensify pain while standing or walking [124]. Further progression of ALN leads to the weakening of tendon reflexes or total areflexia and disturbed proprioception, which additionally impair the ability to walk $[28,113]$. ALN further manifests as weakness and atrophy of muscles due to the damage of greater motor fibers and impaired neuromuscular transmission.

\section{Genetic Background}

Genetic factors and family history of heavy drinking is significantly involved in the pathogenesis of ALN. There is no evidence proving the influence of the human leukocyte antigen (HLA) interindividual variations on the induction of ALN [125]. Masaki et al. (2004) performed a study about the association between Glu-487 $\rightarrow$ Lys mutation (single-nucleotide polymorphism) in aldehyde dehydrogenase-2 (ALDH2) and alcoholic polyneuropathy [126]. Patients with ALDH2*2 (Lys) mutation present poorer ability to metabolize acetaldehyde, an intermediate product of ethanol. Comparisons were made between clinical symptoms and nerve conduction between heterozygotes with mutated allele ALDH2*2/ ALDH2*1 and homozygotes ALDH2*1/ALDH2*1 (Glu487 ) without a mutation. Among alcoholics with a mutated allele, a decrease in sensory action potential amplitudes (SNAP) within the median and sural nerves was shown. The study suggests that acetaldehyde cumulation is significant in ALN etiology. Damages to the median nerve are not very specific for ALN which initially manifests within lower extremities; further, the abovementioned mutation is primarily prevalent in South Asian countries [126].

\section{ALN and Gender}

The prevalence of ALN among the genders is unclear. Females, generally tend to drink less alcohol, are better abstainers, and present the smaller probability of the development of alcohol-related diseases [127, 128]. However, compared to males, the symptoms of excessive alcohol consumption manifest earlier in females [129, 130]. Alcohol-related liver cirrhosis may occur even a few years earlier in females compared to males [131]. The prevalence of alcoholic cardiomyopathy appears to be similar among males and females; however, males present a higher disease burden $[132,133]$. Furthermore, females tend to be more vulnerable to the brain damage and neurotoxic effects of alcohol [134]. Computed tomography (CT) scans showed that among alcoholdependent patients, the brain volumes were reduced to increase the volume of cerebrospinal fluid; these changes were induced in females in less time $[135,136]$. Ammendola et al. (2000) showed an inverse correlation of the sensory-evoked potential (SEP) amplitude of the sural nerve which informs about sensory dysfunctions and is altered even in asymptomatic patients throughout the course alcohol dependence [137]. The correlation was more significant in females. The mouse model of the injection of $\beta$-estradiol in males resulted in higher activity of cytosolic alcohol dehydrogenase (ADH), microsomal aniline hydroxylase (ANH), and aldehyde dehydrogenase (ALDH) which are crucial in ethanol metabolism [138]. Female mouse with injected testosterone showed the decreased activity of cytosolic isoform of ALDH which implies that those enzymes are sensitive to estrogen and testosterone and alcohol metabolism is greater in females.

\section{Malnutrition and Micronutrients Deficiency}

The onset of ALN is intensified by several risk factors such as malnutrition, thiamine deficiency, direct and indirect toxic 
effects of alcohol and its metabolites on nerve fibers, and genetic predispositions of patients [55, 139-143]. It is still unclear what is the major determinant in the pathogenesis of ALN. Primarily, thiamine deficiency is the crucial risk factor of ALN since it induces the progression of Korsakoff's syndrome and beriberi [144, 145]. Due to similar histologic and electrophysiological symptoms, it was believed that ALN may make up a subtype of beriberi [146]. Further research has confirmed the role of thiamine in the pathogenesis of ALN - the well-balanced diet and vitamin B1 supplementation significantly decreased the severity of ALN symptoms $[147,148]$. However, the limitations of those studies include the lack of the possibility to measure the amount of vitamin B1 in the serum; further, patients who were involved in the study have received an unrefined form of the supplement. Later, the results have been supported by Victor and Adams (1961)among 12 patients with ALN, neuropathic symptoms were alleviated just after thiamine supplementation, even though the alcohol consumption was previously completely reduced [149]. Koike et al. (2003) compared clinical and histological differences between ALN with and without thiamine deficiency [65]. Also, the results of the group of 32 patients with nonalcoholic thiamine deficiency neuropathy were considered. Thiamine deficiency resulted in the progression of sensory dysfunctions; further, histological examination of the sural nerves revealed the loss of small nerve fibers and segmental demyelination. Patients with non-alcoholic thiamine deficiency neuropathy showed more abrupt onset of symptoms, mainly in a form of motor dysfunctions; biopsy showed damage to greater fibers with subperineurial edema. ALN with thiamine deficiency was manifested as a variable mixture of these symptoms. It was proposed that ALN pathogenesis, besides thiamine deficiency itself, could be due to its inappropriate use in the organism or transketolase deficiency [150]. Further, alcohol impairs vitamin B1 absorption and its storage in the liver [151-153].

\section{Autonomic Neuropathy}

Alcohol abuse contributes to peripheral neuropathy development involving both somatic and autonomic nerves [154, 155]. However, impairments of autonomic functions are scarcer and less intensified, and, usually, clinical symptoms are delayed [156]. According to many studies, alcoholinduced autonomic neuropathy (AAN) not only leads to potential damage to internal organs but also increases the mortality rate of patients $[157,158]$. It was observed that abstinence may lead to the regression of several symptoms of AAN [159].

The prevalence of impairments in ANS in alcoholdependent patients varies from 20 to $99 \%$ [160]. Symptoms of AAN are due to impairments in both sympathetic and parasympathetic autonomic fibers of the cardiovascular, digestive, and urogenital systems. Appenzeller and Ogin (1974) showed that alcohol-dependent and diabetic patients had a reduced number of large fibers (greater than $5 \mu \mathrm{m}$ ) and greater density of autonomic fibers (possibly because of the degeneration followed by a partial regeneration) [161]. The reduction of internodal length contributes to the decreased speed of nerve conduction which may be implemented in impairments in perspiration, baroreceptor reflexes, and functions of internal organs. To determine the functions of the sympathetic division of the autonomic nervous system (ANS), sympathetic skin response (SSR) is used; the abnormal results of this test suggest subclinical transmission impairments [162]. Navarro et al. (1993) showed that nearly half of the alcohol-dependent patients without AAN symptoms and any aberrations in electrophysiologic studies presented abnormal SSR results [163]. In a similar study, SSR was used to assess the number of reactive sweat glands (SGN), which turned out to be decreased in alcohol-dependent patients [164].

Regarding the parasympathetic division of ANS, most of the studies are focused on the assessment of nerve conduction mainly in oculomotor and vagus nerves; these include pupil cycle time (PCT) and cardiovascular reflex tests correspondingly [160]. Further, ECG changes and functions of the digestive tract (dyspeptic symptoms, stomach and gallbladder motility, orocecal transit time) can also be assessed [162, 165]. PCT seems to be valuable due to the correlation between prolongation of pupil oscillation and exacerbations of cardiovascular symptoms which presents the colinear involvement of parasympathetic division of ANS.

Symptoms of AAN are non-specific; in the sympathetic division, these include impairments in perspiration, orthostatic hypotension, whereas in parasympathetic hoarseness, swallowing difficulties, or cardiac arrhythmias [111, 166]. Gastrointestinal symptoms include delayed stomach emptying and intestinal transit, dyspepsia, and faster emptying of the gallbladder [165]. Besides, approximately $55 \%$ of men with AAN develop erectile dysfunctions [167]. Cardiac arrhythmias in patients with AAN might increase the probability of sudden cardiac death, which is probably due to toxic effects of alcohol on a cardiac muscle that is also observed in alcoholic cardiomyopathy [168, 169].

Other coexisting, alcohol-related diseases may induce exacerbation of AAN symptoms. It was shown that patients with liver cirrhosis (regardless of its etiology) present dysfunctions in ANS, primarily within the vagus nerve [170]. However, the pathogenesis is yet unclear. Proposed mechanisms include circulatory disturbances in liver cirrhosis, metabolic and neurohormonal (renin-angiotensin-aldosterone system) dysfunctions, excessive nitric oxide production, oxidative stress, and inflammatory mediators $[11,171]$. There is a strong correlation between AAN and Child-Pugh scale which suggests that 
liver cirrhosis progression is related to impairments in ANS [172]. Alcohol-abusing patients with liver cirrhosis and vagus nerve neuropathy are at higher risk of a sudden death compared to patients without impairments within the nervous system $[173,174]$.

\section{Treatment}

Treatment of ALN aims to reduce further damage to the peripheral nerves and restore their normal functioning. What is crucial during ALN treatment is the alleviation of the major causation of ALN which is alcohol abuse. Alcohol abuse treatment might lead to a resolution of neuropathic pain and alleviation of its symptoms. This can be achieved by complete alcohol abstinence and a balanced diet primarily supplemented by B6, B12, and E vitamins, as well as folate, thiamine, and niacin. Prevention and treatment of ALN may be also achieved via other alternative treatment strategies including benfotiamine, alpha-lipoic acid, acetyl-L-carnitine, vitamin E, methylcobalamin, myo-inositol, $N$-acetylcysteine, capsaicin, tricyclic antidepressants, or antiepileptic drugs [51]. Benzodiazepines are commonly used to reduce the symptoms of alcohol withdrawal syndrome; acamprosate and naltrexone are effective to treat alcohol dependence; however, the latter usually induces withdrawal symptoms [175]. Cognitivebehavior therapies are suggested to avoid relapses [30]. Further, serotonin-norepinephrine reuptake inhibitors are prescribed to treat alcohol-induced neuropathic pain via exerting antinociceptive properties by increasing serotonergic and noradrenergic neurotransmissions [71]. In an animal model, Kaur et al. (2017) showed that curcumin and sildenafil administrated alone or in combination represent a therapeutic advantage in alcohol-induced neuropathic pain [176].

\section{Conclusions}

Alcohol abuse affects the peripheral and the central nervous system adversely. A common adverse effect of chronic alcohol consumption is alcohol neuropathy. Common symptoms include paresthesias, pain, and ataxia. We do not know precisely how many people are affected by alcohol neuropathy, but research has shown that at least $66 \%$ of chronic alcohol abusers may have some form of neuropathy. Neuropathy has multifactorial causes, ranging from nutritional deficiencies to the toxic effects that alcohol has on neurons. Because of the many effects that alcohol has on the organism, it is important that patients with alcoholic neuropathy be managed by a team of inter-professionals in the health industry. The way alcohol neuropathy is being managed presently is not satisfactory. Treatment is dependent on nutrition and abstinence from alcohol. However, there is poor compliance on the part of patients, resulting in the progression of the condition and ultimately, poor quality of life. Residual neuropathy occurs even in patients who have practiced abstinence. While one may find relief from conventional treatment, the addictive nature or side effects of some medications makes it undesirable to use it for the long term. These treatments, in some cases, only suppress the symptoms but do not treat the underlying pathology. However, alternative therapies do not have side effect and tackle nutritional deficiencies and oxidative stress. Intensive research has been done on medications like alpha-lipoic acid, benfotiamine, acetyl-L-carnitine, and methylcobalamin. Other botanical or nutrient therapies include myo-inositol, vitamin E, topical capsaicin, and $N$-acetylcysteine. Morbidity can be decreased by the use of modern treatment and nutrients.

\section{Compliance with Ethical Standards}

Conflict of Interest The authors declare that they have no conflict of interests.

Human and Animal Rights and Informed Consent This article does not contain any studies with human or animal subjects performed by any of the authors.

Open Access This article is licensed under a Creative Commons Attribution 4.0 International License, which permits use, sharing, adaptation, distribution and reproduction in any medium or format, as long as you give appropriate credit to the original author(s) and the source, provide a link to the Creative Commons licence, and indicate if changes were made. The images or other third party material in this article are included in the article's Creative Commons licence, unless indicated otherwise in a credit line to the material. If material is not included in the article's Creative Commons licence and your intended use is not permitted by statutory regulation or exceeds the permitted use, you will need to obtain permission directly from the copyright holder. To view a copy of this licence, visit http://creativecommons.org/licenses/by/4.0/.

\section{References}

Papers of particular interest, published recently, have been highlighted as:

- Of major importance

1. Grochowski C, Blicharska E, Baj J, Mierzwinska A, Brzozowska $\mathrm{K}$, Forma A, et al. Serum iron, magnesium, copper, and manganese levels in alcoholism: a systematic review. Molecules. 2019;24(7):1361.

2.• Edwards S, Vendruscolo LF, Gilpin NW, Wojnar M, Witkiewitz $\mathrm{K}$. Alcohol and pain: a translational review of preclinical and clinical findings to inform future treatment sstrategies. Alcohol Clin Exp Res. 2020;44(2):368-83. This study provides a comprehensive review of both preclinical and clinical findings that are related to the alcohol abuse and the induction of chronic pain.

3. World Health Organization. Global status report on alcohol and health 2018. World Health Organization 2018; https:// 
wwwwhoint/publications/i/item/global-status-report-on-alcoholand-health-2018 Accessed 24 Jul 2020.

4. Zaridze D, Brennan P, Boreham J, Boroda A, Karpov R, Lazarev A, et al. Alcohol and cause-specific mortality in Russia: a retrospective case-control study of 48,557 adult deaths. Lancet. 2009;373:2201-14.

5. World Health Organization. Global status report on alcohol and health 2011. World Health Organization. 2011; https:// wwwwhoint/substance_abuse/publications/alcohol_2011/en/ Accessed 34 Jul 2020.

6. Rocco A, Compare D, Angrisani D, Sanduzzi Zamparelli M, Nardone G. Alcoholic disease: liver and beyond. World J Gastroenterol. 2014;20(40):14652-9.

7. Ferraguti G, Pascale E, Lucarelli M. Alcohol addiction: a molecular biology perspective. Curr Med Chem. 2015;22(6):670-84.

8. Haas SL, Ye W, Löhr JM. Alcohol consumption and digestive tract cancer. Curr Opin Clin Nutri Metabol Care. 2012;15(5): 457-67.

9. Braillon A. Treatment of alcohol use disorders in patients with liver disease. J Hepatol. 2016;65(6):1270.

10. Harper KM, Knapp DJ, Criswell HE, Breese GR. Vasopressin and alcohol: a multifaceted relationship. Psychopharmacology. 2018;235(12):3363-79.

11. Rehm J, Taylor B, Mohapatra S, Irving H, Baliunas D, Patra J, et al. Alcohol as a risk factor for liver cirrhosis: a systematic review and meta-analysis. Drug Alcohol Rev. 2010;29(4):437-45.

12. Davis BC, Bajaj JS. Effects of alcohol on the brain in cirrhosis: beyond hepatic encephalopathy. Alcohol Clin Exp Res. 2018;42(4):660-7.

13. Singh VK, Yadav D, Garg PK. Diagnosis and management of chronic pancreatitis. Jama. 2019;322(24):2422.

14. Li G, Zhu L, Cao Z, Wang J, Zhou F, Wang X, et al. A new participant in the pathogenesis of alcoholic gastritis: Pyroptosis. Cell Physiol Biochem. 2018;49(1):406-18.

15. Gardner JD, Mouton AJ. Alcohol effects on cardiac function. Comprehen Physiol. 2015;5(2):791-802.

16. Gallagher C, Hendriks JM, Elliott AD, Wong CX, Rangnekar G, Middeldorp ME, et al. Alcohol and incident atrial fibrillation - a systematic review and meta-analysis. Int J Cardiol. 2017;246:4652.

17. Maisch B. Alcoholic cardiomyopathy. Herz. 2016;41(6):484-93.

18. Fernández-Sola J. The effects of ethanol on the heart: alcoholic cardiomyopathy. Nutrients. 2020;12(2):572.

19. Petroni ML, Brodosi L, Marchignoli F, Musio A, Marchesini G. Moderate alcohol intake in non-alcoholic fatty liver disease: to drink or not to drink? Nutrients. 2019;11(12):3048.

20. Arranz S, Chiva-Blanch G, Valderas-Martínez P, Medina-Remón A, Lamuela-Raventós RM, Estruch R. Wine, beer, alcohol and polyphenols on cardiovascular disease and cancer. Nutrients. 2012;4(7):759-81.

21. Cahill PA, Redmond EM. Alcohol and cardiovascular diseasemodulation of vascular cell function. Nutrients. 2012;4(4):297318.

22. Kang YJ, Zhou Z. Zinc prevention and treatment of alcoholic liver disease. Mol Asp Med. 2005;26(4-5):391-404.

23. Zahr NM, Pfefferbaum A. Alcohol's effects on the brain: neuroimaging results in humans and animal models. Alcohol Res. 2017;38(2):183-06.

24. Arts N, Walvoort S, Kessels R. Korsakoff's syndrome: a critical review. Neuropsychiatr Dis Treat. 2017;13:2875-90.

25. Chakravorty S, Chaudhary NS, Brower KJ. Alcohol dependence and its relationship with insomnia and other sleep disorders. Alcohol Clin Exp Res. 2016;40(11):2271-82.

26. Angarita GA, Emadi N, Hodges S, Morgan PT. Sleep abnormalities associated with alcohol, cannabis, cocaine, and opiate use: a comprehensive review. Addict Sci Clin Pract. 2016;11(1):9.
27.• Fama R. Introduction to the special section on alcohol: Review of cognitive, emotional, and neural deficits and recovery with sustained abstinence and treatment. Neuropsychology. 2019;33(6):757-9. This article is of high importance since it provides a comprehensive review regarding the alterations within various systems that are induced by chronic alcohol consumption as well as possible treatment strategies.

28. Hammoud N, Jimenez-Shahed J. Chronic neurologic effects of alcohol. Clin Liver Dis. 2019;23(1):141-55.

29. Grochowski C, Blicharska E, Bogucki J, Proch J, Mierzwinska A, Baj J, et al. Increased aluminum content in certain brain structures is correlated with higher silicon concentration in alcoholic use disorder. Molecules. 2019;24(9):1721.

30. Schuckit MA. Alcohol-use disorders, Lancet. 2009;7;373(9662): 492-501.

31. Monte SMDL, Kril JJ. Human alcohol-related neuropathology. Acta Neuropathol. 2013;127(1):71-90.

32. Martyn CN, Hughes RA. Epidemiology of peripheral neuropathy. J Neurol Neurosurg Psychiatry. 1997;62:310-8.

33. Hoffman E, Staff N, Kabat B, Robb J, St. Sauver J, Klein C. A population based assessment of polyneuropathy and associated disability. American Academy of Neurology, San Diego, CA. Neurology. 2015;84(16):1644-1651.

34. Mygland A, Monstad P. Chronic polyneuropathies in Vest-Agder, Norway. Eur J Neurol. 2001;8:157-65.

35. Staff NP, Windebank AJ. Peripheral neuropathy due to vitamin deficiency, toxins, and medications. CONTINUUM: Lifelong Learn Neurol. 2014;20:1293-306.

36. Katona I, Weis J. Diseases of the peripheral nerves. Handbook of Clinical Neurology Neuropathology. 2018;453-74.

37. Cherry CL, Wadley AL, Kamerman PR. Diagnosing and treating HIV-associated sensory neuropathy: a global perspective. Pain Manag. 2016;6(2):191-9.

38. Straube R, Müller G, Voit-Bak K, Tselmin S, Julius U, Schatz U, et al. Metabolic and non-metabolic peripheral neuropathy: is there a place for therapeutic apheresis? Horm Metab Res. 2019;51(12): 779-84.

39. Newton SC, Marshall S. Effects of anodyne treatment on local blood flow and cutaneous sensation of the foot in a patient with peripheral neuropathy secondary to acromegaly. Physiother Theory Pract. 2019;:1-8.

40. Ungprasert P, Matteson EL. Neurosarcoidosis. Rheum Dis Clin N Am. 2017;43(4):593-606.

41. Boysson HD, Guillevin L. Polyarteritis Nodosa neurologic manifestations. Neurol Clin. 2019;37(2):345-57.

42. Aggarwal D. Prevalence of autonomic neuropathy in patients of rheumatoid arthritis and its correlation with disease severity. J Clin Diagn Res. 2017;11(4):OC09-13.

43. Suliga E, Kozieł D, Ciesla E, Rebak D, Głuszek-Osuch M, Głuszek S. Consumption of alcoholic beverages and the prevalence of metabolic syndrome and its components. Nutrients. 2019;11(11):2764.

44. Skórzyńska-Dziduszko KE, Kimber-Trojnar Ż, Patro-Małysza J, Olszewska A, Zaborowski T, Małecka-Massalska T. An interplay between obesity and inflammation in gestational diabetes mellitus. Curr Pharm Biotechnol. 2016;17:603-13.

45. Rudolph T, Farbu E. Hospital-referred polyneuropathies-causes, prevalences, clinical- and neurophysiological findings. Eur J Neurol. 2007;14:603-8.

46. Ho KWD, Rempe T, Jerath N, Antony A. Dorsal root ganglion stimulation as a potentially effective treatment for painful hereditary and idiopathic axonal polyneuropathy: a retrospective case series. Neuromodulation: Technol Neur Interf. 2019. https://doi. org/10.1111/ner.12924.

47. Bechakra M, Nieuwenhoff MD, Rosmalen JV, Groeneveld GJ, Huygen FJ, Zeeuw CID, et al. Pain-related changes in cutaneous 
innervation of patients suffering from bortezomib-induced, diabetic or chronic idiopathic axonal polyneuropathy. Brain Res. 1730;2020:146621.

48. Hanewinckel R, Ikram MA, Van Doorn PA. Peripheral neuropathies. Handb Clin Neurol. 2016;138:263-82.

49. Munukutla S, Pan G, Deshpande M, Thandavarayan RA, Krishnamurthy P, Palaniyandi SS. Alcohol toxicity in diabetes and its complications: a double trouble? Alcohol Clin Exp Res. 2016;40(4):686-97.

50. Sadowski A, Houck RC. Alcoholic neuropathy. [Updated 2020 Apr 17]. In: StatPearls [Internet]. Treasure Island (FL): StatPearls Publishing; 2020 Jan-. Available from: https://www.ncbi.nlm.nih. gov/books/NBK499856/.

51. Chopra K, Tiwari V. Alcoholic neuropathy: possible mechanisms and future treatment possibilities. Br J Clin Pharmacol. 2012;73(3):348-62.

52. Noble JM, Weimer LH. Neurologic complications of alcoholism. Continuum (Minneap Minn). 2014;20:624-41.

53. Mukherjee S. Alcoholism and its effects on the central nervous system. Curr Neurovasc Res. 2013;10(3):256-62.

54. Mcintosh C, Chick J. Alcohol and the nervous system. J Neurol Neurosurg Psychiatry. 2004;75(3):16-21.

55. Monforte R, Estruch R, Valls-Solé J, Nicolás J, Villalta J, UrbanoMarquez A. Autonomic and peripheral neuropathies in patients with chronic alcoholism: a dose-related toxic effect of alcohol. Arch Neurol. 1995;52(1):45-51.

56. Behse F, Buchthal F. Alcoholic neuropathy: clinical, electrophysiological and biopsy findings. Ann Neurol. 1977;2:95-110.

57. Mellion M, Gilchrist JM, de la Monte S. Alcohol-related peripheral neuropathy: nutritional, toxic, or both? Muscle Nerve. 2011;43(3):309-16.

58. Baj J, Flieger W, Teresiński G, Buszewicz G, Sitarz E, Forma A, et al. Magnesium, calcium, potassium, sodium, phosphorus, selenium, zinc, and chromium levels in alcohol use disorder: a review. J Clin Med. 2020;9(6):1901.

59. Dolar-Szczasny J, Święch A, Flieger J, Tatarczak-Michalewska M, Niedzielski P, Proch J, et al. Levels of trace elements in the aqueous humor of cataract patients measured by the inductively coupled plasma optical emission spectrometry. Molecules. 2019;24:4127.

60. Lettsom JC. Some remarks on the effects of lignum quassiae amarae. Mem Med Soc Lond. 1787;1:128.

61. Jackson J. On a peculiar disease resulting from the use of ardent spirits. N Engl J Med Surg. 1822;11:351.

62. Manji H. Toxic neuropathy. Curr Opin Neurol. 2011;24(5):484 90.

63. Little AA, Albers JW. Clinical description of toxic neuropathies. In: Handbook of Clinical Neurology Occupational Neurology; 2015. p. 253-96

64. Koike H, Mori K, Misu K, Hattori N, Ito H, Hirayama M, et al. Painful alcoholic polyneuropathy with predominant small- fiber loss and normal thiamine status. Neurology. 2001;56:1727-32.

65. Koike H, Iijima M, Sugiura M, Mori K, Hattori N, Ito H, et al. Alcoholic neuropathy is clinicopathologically distinct from thiamine-deficiency neuropathy. Ann Neurol. 2003;54:19-29.

66. Tackmann W, Minkenberg R, Strenge H. Correlation of electrophysiological and quantitative histological findings in the sural nerve of man. Studies on alcoholic neuropathy. J Neurol. 1977;216:289-99.

67. Tredici G, Minazzi M. Alcoholic neuropathy. An electronmicroscopic study. J Neurol Sci. 1975;25:333-46.

68. Laporte A, Richard H, Bonnaud E, Henry P, Vital A, Georgescauld D. A spin label study of myelin fluidity with normal and pathological peripheral nerves. J Neurol Sci. 1979;43:345-6.
69. Zambelis T, Karandreas N, Tzavellas E, Kokotis P, Liappas J. Large and small fiber neuropathy in chronic alcohol-dependent subjects. J Peripher Nerv Syst. 2005;10:375-81.

70. Koike H, Sobue G. Alcoholic neuropathy. Curr Opin Neurol. 2006;19(5):481-6.

71. Vittadini G, Buonocore M, Colli G, Terzi M, Fonte R, Biscaldi G. Alcoholic polyneuropathy: a clinical and epidemiological study. Alcohol Alcohol. 2001;36:393-400.

72. Samantaray S, Knaryan VH, Patel KS, Mulholland PJ, Becker HC, Banik NL. Chronic intermittent ethanol induced axon and myelin degeneration is attenuated by calpain inhibition. Brain Res. 1622;2015:7-21.

73. Savoldi F. Polineuropatie. In: Ceroni M, Camana C, Franciotta DM, Giardini G, Farilla C, Soffiantini F, editors. Lezioni di Neurologia, Vol. 1. Pavia: C.U.S.L; 1995. p. 119-39.

74. Manzo L, Costa LG. Manifestations of neurotoxicity in occupational diseases. In: Costa LG, Manzo L, editors. Occupational Neurotoxicology, vol. 2. Boca Raton: CRC Press; 1998. p. 1-20.

75. Mellion ML, Silbermann E, Gilchrist JM, Machan JT, Leggio L, de la Monte S. Small-fiber degeneration in alcohol-related peripheral neuropathy. Alcohol Clin Exp Res. 2014;38(7):1965-72.

76. Zeng L, Alongkronrusmee D, van Rijn RM. An integrated perspective on diabetic, alcoholic, and drug-induced neuropathy, etiology, and treatment in the US. J Pain Res. 2017;20(10):219-28.

77. Ammendola A, Tata MR, Aurilio C, Ciccone G, Gemini D, Ammendola E, et al. Peripheral neuropathy in chronic alcoholism: a retrospective cross-sectional study in 76 subjects. Alcohol Alcohol. 2001;36(3):271-5.

78. Estruch R, Nicolás JM, Villegas E, Junqué A, Urbano-Márquez A. Relationship between ethanol-related diseases and nutritional status in chronically alcoholic men. Alcohol Alcohol. 1993;28:54350 .

79. Kaufmann A. Lead in wine. Food Addit Contam. 1998;15(4): 437-45.

80. Ferdinandis TGHC, De Silva HJ. Illicit alcohol consumption and neuropathy-a preliminary study in Sri Lanka. Alcohol Alcohol. 2008;43:171-3.

81. Dina OA, Gear RW, Messing RO, Levine JD. Severity of alcoholinduced painful peripheral neuropathy in female rats: role of estrogen and protein kinase (A and $\mathrm{C}$ epsilon) Neuroscience. 2007:145:350-6.

82. Frank LL. Thiamin in clinical practice. J Parenter Enter Nutr. 2015;39(5):503-20.

83. Callaghan BC, Price RS, Chen KS, Feldman EL. The importance of rare subtypes in diagnosis and treatment of peripheral neuropathy. JAMA Neurol. 2015;72(12):1510.

84. Kucera P, Balaz M, Varsik P, Kurca E. Pathogenesis of alcoholic neuropathy. Bratisl Lek Listy. 2002;103(1):26-9.

85. Costardi JVV, Nampo RAT, Silva GL, Ribeiro MAF, Stella HJ, Stella MB, et al. A review on alcohol: from the central action mechanism to chemical dependency. Revista da Associaćčo Médica Brasileira. 2015;61(4):381-7.

86. Abrahao KP, Salinas AG, Lovinger DM. Alcohol and the brain neuronal molecular targets, synapses, and circuits. Neuron. 2017;96(6):1223-38.

87. Montesinos J, Alfonso-Loeches S, Guerri C. Impact of the innate immune response in the actions of ethanol on the central nervous system. Alcohol Clin Exp Res. 2016;40(11):2260-70.

88. Thomson AD. Mechanisms of vitamin deficiency in chronic alcohol misusers and the development of the Wernicke-Korsakoff syndrome. Alcohol Alcohol. 2000;35(Supplement_1):2-1.

89. Daré BL, Lagente V, Gicquel T. Ethanol and its metabolites: update on toxicity, benefits, and focus on immunomodulatory effects. Drug Metab Rev. 2019;51(4):545-61.

90. Takeuchi M, Saito T. Cytotoxicity of acetaldehyde-derived advanced glycation end-products (AA-AGE) in alcoholic-induced 
neuronal degeneration. Alcohol Clin Exp Res. 2005;29(Suppl.): 220S-4S.

91. Chen CH, Ferreira JC, Gross ER, Mochly-Rosen D. Targeting aldehyde dehydrogenase 2: new therapeutic opportunities. Physiol Rev. 2014;94(1):1-34.

92. Henriques JF, Portugal CC, Canedo T, Relvas JB, Summavielle T, Socodato R. Microglia and alcohol meet at the crossroads: microglia as critical modulators of alcohol neurotoxicity. Toxicol Lett. 2018;283:21-31.

93. Walter TJ, Vetreno RP, Crews FT. Alcohol and stress activation of microglia and neurons: brain regional effects. Alcohol Clin Exp Res. 2017;41(12):2066-81.

94. Crews FT, Lawrimore CJ, Walter TJ, Coleman LG. The role of neuroimmune signaling in alcoholism. Neuropharmacology. 2017;122:56-73.

95. Kumar J, Ismail Z, Hatta NH, Baharuddin N, Hapidin H, Bee YTG, et al. Alcohol addiction- metabotropic glutamate receptor subtype 5 and its ligands: how they all come together? Curr Drug Targets. 2018;19(8):907-15.

96. Rachdaoui N, Sarkar DK. Effects of alcohol on the endocrine system. Endocrinol Metab Clin N Am. 2013;42(3):593-615.

97. Ferrari L, Levine E, Levine J. Independent contributions of alcohol and stress axis hormones to painful peripheral neuropathy. Neuroscience. 2013;228:409-17.

98. Reddy VD, Padmavathi P, Bulle S, Hebbani AV, Marthadu SB, Venugopalacharyulu N, et al. Association between alcoholinduced oxidative stress and membrane properties in synaptosomes: a protective role of vitamin E. Neurotoxicol Teratol. 2017;63:60-5.

99. Hu Q, Wei J, Liu Y, Fei X, Hao Y, Pei D, et al. Discovery and identification of potential biomarkers for alcohol-induced oxidative stress based on cellular metabolomics. Biomedical Chromatography. 2017;31(7).

100. Roberto M, Patel RR, Bajo M. Ethanol and cytokines in the central nervous system. The Neuropharmacology of Alcohol Handbook of Experimental Pharmacology. 2017;397-431.

101. Leclercq S, Timary PD, Delzenne NM, Stärkel P. The link between inflammation, bugs, the intestine and the brain in alcohol dependence. Translat Psychiatry. 2017;7(2).

102. Nguyen VA, Le T, Tong M, Mellion M, Gilchrist J, Monte SMDL. Experimental alcohol-related peripheral neuropathy: role of insulin/IGF resistance. Nutrients. 2012;4(8):1042-57.

103. Nguyen VA, Le T, Tong M, Silbermann E, Gundogan F, Monte SMDL. Impaired insulin/IGF signaling in experimental alcoholrelated myopathy. Nutrients. 2012;4(8):1058-75.

104. Manzo-Avalos S, Saavedra-Molina A. Cellular and mitochondrial effects of alcohol consumption. Int J Environ Res Public Health. 2010;7(12):4281-304.

105. Ludin HP, Tackman W. Polyneuropathien. Stuttgart: Georg Thieme Verlag; 1984. p. 250-5.

106. McLane JA. Decreased axonal transport in rat nerve following acute and chronic ethanol exposure. Alcohol. 1987:4:385-9.

107. Hellweg R, Baethge C, Hartung HD, Brückner MK, Arendt T. NGF level in the rat sciatic nerve is decreased after long-term consumption of ethanol. Neuroreport. 1996;7:777-80.

108. Malatova Z, Cizkova D. Effect of ethanol on axonal transport of cholinergic enzymes in rat sciatic nerve. Alcohol. 2002;26:11520.

109. Mawdsley C, Mayer RF. Nerve conduction in alcoholic polyneuropathy. Brain. 1965;88:335-56.

110. Thiele B, StĆlberg E. Single fibre EMG findings in polyneuropathies of different aetiology. J Neurol Neurosurg Psychiatry. 1975;38:881-7.

111. Johnson RH, Eisenhofer G, Lambie DG. The effects of acute and chronic ingestion of ethanol on the autonomic nervous system. Drug Alcohol Depend. 1986;18(4):319-28.
112. Bednarik J, Vlckova-Moravcova E, Bursova S, Belobradkova J, Dusek L, Sommer C. Etiology of small-fiber neuropathy. J Peripher Nerv Syst. 2009;14(3):177-83.

113. Schuchardt V. Alcohol and the peripheral nervous system. Ther Umsch. 2000;57(4):196-9.

114. Watson JC, Dyck PJB. Peripheral neuropathy: a practical approach to diagnosis and symptom management. Mayo Clin Proc. 2015;90(7):940-51.

115. Hughes RAC. Peripheral neuropathy. BMJ. 2002;324(7335):466469.

116. Terkelsen AJ, Karlsson P, Lauria G, Freeman R, Finnerup NB, Jensen TS. The diagnostic challenge of small fibre neuropathy: clinical presentations, evaluations, and causes. Lancet Neurol. 2017;16(11):934-44.

117. Barrell K, Smith AG. Peripheral neuropathy. Med Clin N Am. 2019;103(2):383-97.

118. Victor M. The effects of alcohol on the nervous system. In: Mendelson JH, Mello NK, editors. Medical diagnosis and treatment of alcoholism. New York: McGraw-Hill, Inc.; 1992. p. 20162.

119. Watson JC. Central neuropathic pain: syndromes, pathophysiology, and treatments. Clin Pain Manag. 2008;374-87.

120. Cohen SP, Mao J. Neuropathic pain: mechanisms and their clinical implications. Bmj. 2014;348(feb05 6).

121. Zilliox LA. Neuropathic pain. CONTINUUM: Lifelong Learn Neurol. 2017;23(2):512-32.

122. Smith ESJ. Advances in understanding nociception and neuropathic pain. J Neurol. 2017;265(2):231-8.

123. Otis J, Macone A. Neuropathic pain. Semin Neurol. 2018;38(06): 644-53.

124. Rajani P. Maiya, Robert O. Messing, Peripheral systems: neuropathy, Handbook of Clinical Neurology Volume 125, 2014, pp. 513-525.

125. Rösler M, Bellaire W, Hengesch G, Giannitsis D, Jarovici A. Genetic markers in alcoholism: no association with HLA. Arch Psychiatr Nervenkr. 1983;233:327-31.

126. Masaki T, Mochizuki H, Matsushita S, Yokoyama A, Kamakura K, Higuchi S. Association of aldehyde dehydrogenase-2 polymorphism with alcoholic polyneuropathy in humans. Neurosci Lett. 2004;363:288-90.

127. Erol A, Karpyak VM. Sex and gender-related differences in alcohol use and its consequences: contemporary knowledge and future research considerations. Drug Alcohol Depend. 2015;1(156):113.

128. Langenau B, Bergmann N, Oluwagbemigun. The association between alcohol consumption and serum metabolites and the modifying effect of smoking. Nutrients. 2019;11(10):2331.

129. Ashley MJ, Olin JS, le Riche WH, Kornaczewski A, Schmidt W, Rankin JG. Morbidity in alcoholics. Evidence for accelerated development of physical disease in women. Arch Intern Med. 1977;137(7):883-7.

130. Loft S, Olesen KL, Dossing M. Increased susceptibility to liver disease in relation to alcohol consumption in women. Scand $\mathrm{J}$ Gastroenterol. 1987;22:1251-6.

131. Saunders JB, Davis M, Williams R. Do women develop alcoholic liver disease more readily than men? Bmj. 1981;282(6270):1140 3.

132. Piano MR, Phillips SA. Alcoholic cardiomyopathy: pathophysiologic insights. Cardiovasc Toxicol. 2014;14(4):291-308.

133. Piano MR. Alcoholic cardiomyopathy. J Am Coll Cardiol. 2018;71(20):2303-5.

134. Prendergast MA. Do women possess a unique susceptibility to the neurotoxic effects of alcohol? J Am Med Wom Assoc. 2004;59: $225-7$. 
135. Jacobson R. The contributions of sex and drinking history to the CT brain scan changes in alcoholics. Psychol Med. 1986;16:54759.

136. Mann K, Batra A, Gunther A, Schroth G. Do women develop alcoholic brain damage more readily than men? Alcohol Clin Exp Res. 1992;16:1052-6.

137. Ammendola A, Gemini D, Iannaccone S, Argenzio F, Ciccone G, Ammendola E, et al. Gender and peripheral neuropathy in chronic alcoholism: a clinical-electroneurographic study. Alcohol Alcohol. July 2000;35(4):368-71.

138. Kishimoto R, Ogishi Y, Ueda M, Matsusaki M, Amako K, Goda $\mathrm{K}$, et al. Gender-related differences in mouse hepatic ethanol metabolism. J Nutr Sci Vitaminol (Tokyo). 2002;48:216-24.

139. Victor M. Polyneuropathy due to nutritional deficiency and alcoholism. In: Dyck PJ, Thomas PK, Lambert EH, editors. Peripheral neuropathy. Philadelphia: W. B. Saunders; 1975. p. 1030-66.

140. Bosch EP, Pelham RW, Rasool CG, Chattorjee A, Lasch RW, Brown L. Animal models of alcoholic neuropathy: morphological, electrophysiological and biochemical findings. Muscle Nerve. 1979;2:133-44.

141. Pessione F, Gerchstein JL, Rueff B. Parental history of alcoholism: a risk factor for alcohol-related peripheral neuropathies. Alcohol Alcohol. 1995;30:749-54.

142. Huas D, Allemand H, Loiseau D, Pessione F, Rueff B. Prévalence du risque et des maladies liés ą l'alcool dans la clientŹle adulte du généraliste. Revue du Praticien: Med Gen. 1993;7:39-44.

143. Hamel J, Logigian EL. Acute nutritional axonal neuropathy. Muscle Nerve. 2017;57(1):33-9.

144. Chandrakumar A, Bhardwaj A, Jong GW'T. Review of thiamine deficiency disorders: Wernicke encephalopathy and Korsakoff psychosis. J Basic Clin Physiol Pharmacol. 2018;30(2):153-62.

145. Whitfield KC, Bourassa MW, Adamolekun B, Bergeron G, Bettendorff L, Brown KH, et al. Thiamine deficiency disorders: diagnosis, prevalence, and a roadmap for global control programs. Ann N Y Acad Sci. 2018;1430(1):3-43.

146. Shattuck GC. The relation of beri-beri to polyneuritis from other causes. Am J Trop Med. 1928;8:539-43.

147. Minot GR, Strauss MB, Cobb S. Alcoholic polyneuritis: dietary deficiency as a factor in its production. N Engl J Med. 1933;208: 1244-9.

148. Strauss MB. The etiology of alcoholic polyneuritis. Am J Med Sci. 1935; 189:378-82.

149. Victor M, Adams RD. On the etiology of alcoholic neurologic diaseases with special reference to the role of nutrition. Am J Clin Nutr. 1961;9:379-97.

150. Paladin F, Russo PG. The haematic thiamine level in the course of alcoholic neuropathy. Eur Neurol. 1987;26:129-33.

151. Hoyumpa AM. Mechanism of thiamine deficiency in chronic alcoholism. Am J Clin Nutr. 1980;3:2759-61.

152. Tomasulo PA, Katner RM, Iber FL. Impairment of thiamine absorption in alcoholism. Am J Clin Nutr. 1968;21:1340-4.

153. Leevy CM, Baker H, Ten Hove W, Frank O, Cherrick GR. Bcomplex vitamins in liver disease of the alcoholic. Am J Clin Nutr. 1965;16:339-46.

154. Agelink MW, Malessa R, Weisser U, Lemmer W, Zeit T, Majewski T, et al. Alcoholism, peripheral neuropathy (PNP) and cardiovascular autonomic neuropathy (CAN). J Neurol Sci. 1998;161:135-42.

155. Ciaula AD, Grattagliano I, Portincasa P. Chronic alcoholics retain dyspeptic symptoms, pan-enteric dysmotility, and autonomic neuropathy before and after abstinence. J Dig Dis. 2016;17(11):73546.

156. Low PA, Walsh JC, Huang CY, McLeod JG. The sympathetic nervous system in alcoholic neuropathy. A clinical and pathological study. Brain. 1975;98(3):357-64.
157. Milovanovic B, Milinic N, Trifunovic D, Krotin M, Filipovic B, Bisenic V, et al. Autonomic dysfunction in alcoholic cirrhosis and its relation to sudden cardiac death risk predictors. Gen Physiol Biophys. 2009;28:251-61.

158. Johnson RH, Robinson BJ. Mortality in alcoholic with autonomic neuropathy. J Neurol Neurosurg Psychiatry. 1988;51:476-80.

159. Tan ET, Johnson RH, Lambie DG, Whiteside EA. Alcoholic vagal neuropathy: recovery following prolonged abstinence. J Neurol Neurosurg Psychiatry. 1984;47(12):1335-7.

160. Miralles R, Espadaler JM, Navarro X, Rubiés-Prat J. Autonomic neuropathy in chronic alcoholism: evaluation of cardiovascular, pupillary and sympathetic skin responses. Eur Neurol. 1995;35(5):287-92.

161. Appenzeller O, Ogin G. Myelinated fibres in human paravertebral sympathetic chain: white rami communicantes in alcoholic and diabetic patients. J Neurol Neurosurg Psychiatry. 1974;37(10): 1155-61.

162. Nazliel B, Arikan Z, Irkeć C, Karakilić H. SSR abnormalities in chronic alcoholics. Addict Behav. 2007;32(6):1290-4.

163. Navarro X, Miralles R, Espadaler JM, Rubiés-Prat J. Comparison of sympathetic sudomotor and skin responses in alcoholic neuropathy. Muscle Nerve. 1993;16(4):404-7.

164. Kennedy WR, Navarro X. Sympathetic sudomotor func- tion in diabetic neuropathy. Arch Neurol. 1989;46:1182-6.

165. Di Ciaula A, Grattagliano I, Portincasa P. Chronic alcoholics retain dyspeptic symptoms, pan-enteric dysmotility, and autonomic neuropathy before and after abstinence. J Dig Dis. 2016;17(11): 735-46.

166. Melgaard B, Somnier F. Cardiac neuropathy in chronic alcoholics. Clin Neurol Neurosurg. 1981;83(4):219-24.

167. Ravaglia S, Marchioni E, Costa A, Maurelli M, Moglia A. Erectile dysfunction as a sentinel symptom of cardiovascular autonomic neuropathy in heavy drinkers. J Peripher Nerv Syst. 2004;9(4): 209-14.

168. Kupari M., Koskinen P. Alcohol, cardiac arrhythmias and sudden death. Novartis Found Symp 1998;216:68-79; discussion 79-85.

169. Yokoyama A, Ishii H, Takagi T, Hori S, Matsushita S, Onishi S, et al. Prolonged QT interval in alcoholic auto- nomic nervous dysfunction. Alcohol Clin Exp Res. 1992;16:1090-2.

170. Dillon JF, Plevris JN, Nolan J, Ewing DJ, Neilson JM, Bouchier IA, et al. Autonomic function in cirrhosis assessed by cardiovascular reflex tests and 24-hour heart rate variability. Am J Gastroenterol. 1994;89:1544-15447.

171. Muller S, Henriksen JH. Cardiovascular complications of cirrhosis. Gut. 2008;57:268-78.

172. Henriksen JH, MN̦ller S, Ring-Larsen H, Christensen NJ. The sympathetic nervous system in liver disease. J Hepatol. 1998;29: $328-41$.

173. Hendrickse MT, Triger DR. Peripheral and cardiovas- cular autonomic impairment in chronic liver disease: prevalence and relation to hepatic function. J Hepatol. 1992;16:177-83.

174. Fleckenstein JF, Frank S, Thuluvath PJ. Presence of autonomic neuropathy is a poor prognostic indicator in patients with advanced liver disease. Hepatology. 1996;23:471-5.

175. Liang J, Olsen RW. Alcohol use disorders and current pharmacological therapies: the role of GABAA receptors. Acta Pharmacol Sin. 2014;35(8):981-93.

176. Kaur M, Singh A, Kumar B, Singh SK, Bhatia A, Gulati M, et al. Protective effect of co-administration of curcumin and sildenafil in alcohol induced neuropathy in rats. Eur J Pharmacol. 2017;805: $58-66$.

Publisher's Note Springer Nature remains neutral with regard to jurisdictional claims in published maps and institutional affiliations. 